\title{
COLLECTIVE EMPLOYMENT CONTRACTS AND NEW WORKING TIME ARRANGEMENTS IN NEW ZEALAND
}

\author{
Raymond Harbridge and David Tolich \\ Victoria University of Wellington
}

The pressure for change to collectively negotiated working time arrangements has altered dramatically over the last 30 years, reflecting in part the reversal of fortunes experienced by labour movements and the world wide recession of the 1980 s and 1990s. In OECD countries during the period of economic growth of the 1960 s and 1970 s, labour driven pressure was for a reduction of the standard working week. This was most clearly observed in the German economy where the average number of hours worked per year dropped from 2316 hours in 1950 to 1737 hours by 1975 . The pressure in Germany was maintained but further reductions were delayed until 1984 (in part due to the contraction of growth) when the negotiation of a 38.5 hour week followed increased industrial unrest by German unions (Bosch, 1990). More recently, in 1990, in the important metal industry, these hours were further reduced to 35 per week following negotiations.

Reductions in annual and weekly hours were almost always justified on the basis of increased productivity however Neifer-Dichmann (1991) argues that working time was reduced without the trade-off of increased productivity. She argues that differentiation of working time, rather than a simple overall reduction, should be linked to production demands and that this did not occur. Restraint in generalising about cause and effect relationships between productivity and reduced working hours needs to be exercised as the relationships are complex and differ according the sector and the economy under examination (Anxo and Bigsten, 1989) however it was inevitable that consideration of flexibilisation issues would be drawn into the debate.

The German phenomenon has been experienced in other $\mathrm{OECD}$ countries with trends being towards a reduction in the working week for full time workers (Melvyn, 1991). The drive for shorter hours within the European Community is reinforced by the Community Charter of Fundamental Social Rights of Workers (Social Charter), particularly the EC draft Directive on Working Time (Blyton, 1992). In Japan, the 1992 Shunto (spring wage offensive) saw the reduction of working hours as the major union claim. RENGO, the Japanese peak union organisation, attempted to trade a reduction in hours for a low pay increase. Japanese employers, even with a contracting economy, high productivity and shrinking overtime, resisted the trade-off citing as their major concern about possible falls in productivity if less hours are worked (Do Rosario, 1992).
The concerns of Japanese employers are somewhat universal. Different pressures have emerged, in the 1980 s and 1990 s where the economic recession, coupled with rapidly changing product markets and the requirement for more flexible production methods, has led to employer driven pressure for greater flexibility in working time arrangements (Brunhes et al, 1989; Storper and Scott, 1990) particularly when faced with union claims for shorter hours (Bosch, 1990). While the predominant pressure for working time flexibility is employer driven and designed to enable employers to change the arrangement of work hours to match the fluctuations in work demand, it can also allow employees to change work patterns to match their other time demands and preferences (Blyton,1985), an important consideration given the very different societal patterns that have emerged in the last decade. The driving force for flexibilisation in working time remains however employer driven and the growth of structural unemployment (currently 31 million in the OECD) coupled with its acceptance by most Governments (Macarov, 1991), makes job security a major factor to be traded in negotiations over flexibility in a restructured working environment .

Changes to hours of work and working time arrangements then have become one of the key adjustment strategies used to achieve labour market flexibility. These strategies exist within the broader context of management's search for greater flexibility to respond to increasing competition in the marketplace. The drive for efficiency in the face of increasing uncertainty and retention of current market share requires greater cost effectiveness, more efficient work scheduling, increased responsiveness to change and improved availability of service. To achieve these efficiencies, working time pattems must closely match patterns of work demands. At the enterprise level, the employer's ability to adjust hours of work according to the demands of production, while keeping the overall numbers of workers constant, has become a key objective. Related employer adjustment strategies include "annual hours", holiday arrangements, shift (including temporary shift) work, the use of flexitime, overtime, variable work weeks, and short-time working (Blyton, 1992).

Annual hours have been used by some employers as a means of avoiding overtime and penal rates of pay. The overall objective is the minimisation of the total work/ labour hours scheduled. Workers are contracted to work a given number of hours a year on a fixed rate. The 
arrangement of working time and the allocation of staffing schedules is within the constraint of fixed hours, in order to reduce overstaffing and overtime payments (Loucks and Jacob, 1991; Bechtold et. al. 1991). The success of this form of adjustment is varied. In the UK for example, women workers in the television industry are now viewing the effects as discriminatory. However, in parts of the food industry, the workforce is happy with the predictability of work schedules and constancy of production has been achieved within a fixed annual number of hours, with a raised flat rate of pay and no overtime payments. Some local authorities report an increased ability in consistency of forward planning, despite union and worker opposition (Charlton, 1991; Pickard, 1992).

Adjustment strategies and changes to working time arrangements such as those just listed, are often limited by regulation - whether that be statute or collective bargain. In Europe, the regulation of working hours and annual holidays occurs in every country except the UK (where there is a general absence of statutory provision) which alone opposes the creation of the Social Charter of Workers Rights (Mayer, 1991). Among the conditions proposed in the Social Charter are that maximum daily hours be limited to 13; that rest days must be one day in 7; and that night work is limited to an average of 8 hours in any 24 hour period, taken over a 14 day period. The draft Directive on Working Time attempts to respond to the changing patterns of working time. The Directive aims to give workers additional protections that attempt to limit the freedom of management in issues of labour deployment as well as duration (Blyton, 1992).

In New Zealand, the statutory regulation of working time remained unchanged for many years and were (until the employment contracts legislation of 1991) most recently contained in S172 of the Labour Relations Act 1987. The Act prescribed that every collective bargain should fix "at not more than 40" the maximum number of hours (exclusive of overtime) that could be worked by any worker bound by a document and that the parties should endeavour to fix the daily working hours so that no part of the working period fell on a Saturday or a Sunday. Further, a weeks work could exceed 40 hours (exclusive of overtime) should the parties agree. Thus the Act intended, but did not explicitly provide for, a 40 hour week to be worked over 5 days excluding Saturday and Sunday. Overtime and penal rates were seen as the mechanism for enabling work outside these regular hours and in practice no settlements provided for ordinary hours in excess of $\mathbf{4 0}$ per week.

Following legislative changes in 1984 and 1987 which enhanced their power in collective bargaining, employers started to press for greater flexibility in hours of work provisions (Harbridge and McCaw, 1989). In successive bargaining rounds since 1987, approximately one third of all settlements registered with the Arbitration Commission contained a change to working time arrangements. A detailed analysis of the changes for one bargaining round (1987/8) shows that 80 percent of the changes to working time clauses produced a more liberal arrangement for employers (Harbridge and Dreaver, 1989).

The Labour Relations Act 1987 was repealed and replaced by the Employment Contracts Act 1991 - an Act that leaves both the type and content of all employment contracts completely over to the parties to determine and accordingly, where there is no mention of a 40 hour, 5 day week. The provisions of S172 of the Labour Relations Act were not however discarded but were transferred to S11B of the Minimum Wage Act without the requirement that the 5 days should be scheduled so as to avoid Saturday and Sunday work. The altered placement and liberalisation of the legislative provisions, along with the general decollectivising thrust of the Act offers employers greater incentives to alter working time arrangements.

The transitional arrangements provided for in the Employment Contracts Act meant that existing settlements continued in force until their nominal expiry but by now, October 1992, there are just 65 of these settlements (covering less than 20,000 workers) that have not reached their expiry date. The Employment Contracts Act is in full force.

The research reported in this paper examines the impact in New Zealand of the liberalisation of the statutory regulation on working time in collective employment contract bargaining. Specifically this research reports working time arrangements that are changed in three areas. First, the reduction (or extension) of the working week thus decreasing (or increasing) the number of hours worked by full time workers. Second, the scheduling of the hours worked each week by full time workers. Here changes to the span of days available (and whether that span includes weekend days) and the span of hours available for ordinary work each day have been identified. Third, the application of overtime payments and the specific overtime rate has been examined.

\section{Methodology}

The outcomes of the collective bargaining process in New Zealand have been a matter of public record from the 1890s until 1991. The Arbitration Commission or Court (whichever it was according to the whim of the Government of the day) provided each year, neatly bound as The Book of Awards, the complete content of every award or other collective settlement that it registered. Further an appendix was provided to enable the easy identification of each settlement by type and industry or occupational basis. Until 1987, the Book of Awards was freely ${ }^{1}$ available to institutions such as unions, employers organisations, public and law libraries and Industrial Relations Centres in Universities. With the introduction of the Labour Relations Act 1987, publication in the Book of Awards was restricted to multi-employer awards (and composite awards) while registered enterprise settlements (agreement and composite agreements) were available in a "loose-leaf" format. Collective bargains remained part of the public record, 
though no longer without cost - user pays policies ensured that the costs of both the bound Book of Awards and the loose leaf subscriptions were met by those requiring same.

The Employment Contracts Act 1991 contains a very different thrust than that of New Zealand's earlier industrial relations legislation. That thrust is directed at the decollectivisation of the labour relations system, encouraging enterprise bargaining over multi-employer bargaining, and promoting individual rights as equal to those of any collective. A direct corollary of these policies is reflected in the decision to keep no public record of collective bargains. Confidentiality of settlement outcomes has become an important aspect of negotiations.

While Government policy has determined that there will be no public record of collective bargains, it has decided that, for "analytical and research" purposes, employers who enter into collective employment contracts that cover 20 or more staff should forward copies of those contracts to the Secretary of Labour. No such obligation rests with unions or other employee organisations who enter into contracts.

In the absence of a comprehensive public record of collective bargaining, primary data gathering has become a necessary first step for any comprehensive review of the effects of the employment contracts legislation. For the research reported herein, primary data gathering has consisted of attempting to collect as many collective employment contracts as is possible, irrespective of the size of each contract. A multi-faceted approach to this data gathering has been adopted and a number of surveys undertaken. Complete confidentiality has been offered to all taking part in these surveys.

The first survey has been of employers of 50 or more staff as listed in the New Zealand Business Who's Who. There are 1200 employers (with a total of 430,000 staff) listed as having 50 or more staff. In the period August October 1991, these employers were asked whether they would be prepared to forward copies of their collective employment contracts as part of this research project. As at August 1992,800 employers (280,000 staff) had replied - 67 percent of those surveyed.

Of the 800 respondents, 175 employers ( 93,000 staff) have already forwarded collective employment contracts and a further 242 employers (52,000 staff) offered to forward contracts when they were settled. 163 employers $(59,000$ staff $)$ indicated they did not want to take part in the survey (confidentiality being the most quoted reason for not wanting to take part) and 174 employers (with just 47,000 staff) indicated they would be negotiating individual contracts only. A settlement registered under the Labour Relations Act 1987 which has been taken as an indication that support for the project is forthcoming was forwarded by 25 employers (25,000 staff).
The second survey of employers has been undertaken of employers of 20 - 50 staff as listed in the New Zealand Business Who's Who. There are 1400 employers (with a total of 43,000 staff) listed as having between 20 and 50 staff. These employers were written to in June and July 1992 and asked to take part in the study. As at August 1992, 35 percent of those surveyed had replied.

The third survey has been of unions. At 15 May 1991 there were some 80 unions registered under the Labour Relations Act. All of these have been asked if they will supply collective employment contracts as part of the monitoring project. The response has been encouraging with only three unions refusing to supply the collective employment contracts they have negotiated. Union resources have been heavily taxed during this period and forwarding contracts was unlikely to have been a high priority. Accordingly, regular contact with officials has been an important aspect in maximising coverage with unions.

Other surveys include public sector bargaining (of which there had been little finalised as at August 1992) and the State Services Commission has agreed formally to supply copies of contracts they are associated with: of bargaining agents, some of whom have agreed to endorse the project to their clients; the monitoring of news reports for evidence of the negotiations of and disputes over collective employment contracts; finally personal contacts in the labour relations "industry" are ensuring good source collection.

A very detailed analysis of the changes to different types of working time arrangements - particularly clock hours, and penal and overtime rates - in collective employment contracts has been undertaken for this paper. Wherever possible, the condition in the new contract has been compared with the previous condition in the relevant predecessor award or collective agreement. In reporting data, the number of contracts and the number of workers covered by that contract is presented. Further, the number of predecessor awards or collective agreements from which the new contracts have been derived is also reported. The number of workers covered by these "old" settlements is not the total number of workers covered by these old awards etc, but is the number of workers covered by the contract replacing that award - this enables a better analysis of the patterns of change to be made.

\section{The sample of contracts}

The sample of collective employment contracts reported herein is the contracts gathered as at 10th August 1992. The sample contained 770 contracts covering 166,000 workers. Union supplied 416 contracts covering 83,000 workers, employers supplied 301 contracts covering 58,000 workers and 52 contracts covering 25,000 workers were supplied by both unions and employers. 
Table 1: The distribution and coverage of contracts by industry

Industry

Manufacturing

Wholesale, retail, hotel etc

Transport, communication

Finance

Community, public services

Other

Totals
No. of Contracts

364

70

62

58

131

83

769
Coverage

31872

32382

26633

34850

29954

9915

165606

\section{\% Coverage}

$19 \%$

$20 \%$

$16 \%$

$21 \%$

$18 \%$

$6 \%$

$100 \%$
The contracts in the sample are from a spread of industries, though some industries dominate. The distribution and coverage of contracts is presented in Table 1.

It is well known that major changes to working time arrangements have occurred in the retail sector, however retailing is a sector that has largely declined to supply contracts for this project. In our sample, just 31 contracts covering 14,000 employees are in the retail sector. Accordingly the radical changes in retail do not overinfluence the general patterns of change reported in this paper. The contracts in this sample do not include those settlements made in the public service following the expiry of many old awards and collective agreements in the "state" sector on 30 June 1992. A large number of the contracts reported herein and classified as "community, public services" are in the local government sector.

\section{Results}

\section{The Reduction / Extension of Ordinary Hours}

The ordinary hours of work never exceeded 40 per week under the former system, and many awards provided for a 37.5 hour week. We have identified 53 new employment contracts covering 7,400 workers that have ordinary hours in excess of $\mathbf{4 0}$ per week. Apart from this, there is little evidence of the widespread extension of the ordinary hours of work and ordinary hours of work per week have remained much as before. Despite claims to the contrary elsewhere, workers who previously were on a $\mathbf{3 7 . 5}$ hour week seem largely to have retained those hours. The data are presented in Table 2.

\section{Changed Scheduling Arrangements: "Clock Hours"}

A "clock hours" clause typically states that normal hours of work, paid at ordinary rates of pay, will fall between fixed hours (eg $8 \mathrm{am}$ to $6 \mathrm{pm}$ ) on specified days during the week (eg Monday to Friday). Where there is no clock hours clause, the employer has greater discretion over the days of the week and the hours of each day, within which the "week's work" can be arranged without attracting overtime payments. An alternative way of avoiding penal rates and overtime payments is to provide for regular shift work in the contract. Many contracts provide for shift work arrangements with 385 contracts covering 111,000 workers having some shift arrangements specified.

Clock hours of the traditional type exist in 557 contracts ( 72 percent of all contracts) covering 116,000 workers ( 70

Table 2 Changed ordinary hours of work per week

\begin{tabular}{|c|c|c|c|c|}
\hline \multirow[b]{2}{*}{ Hours per week } & \multicolumn{2}{|c|}{ Previous settlement } & \multicolumn{2}{|c|}{ New contract } \\
\hline & No. & Coverage & No. & Coverage \\
\hline 35 hours & 2 & 57 & 2 & 55 \\
\hline 37.5 hours & 59 & 36370 & 72 & 35941 \\
\hline 38 hours & 5 & 9015 & 4 & 8804 \\
\hline 40 hours & 517 & 93599 & 582 & 103086 \\
\hline 42.5 hours & - & - & 4 & 279 \\
\hline 44 hours & - & - & 6 & 1573 \\
\hline 45 - 49 hours & - & - & 13 & 1079 \\
\hline 50 hours & - & - & 23 & 3810 \\
\hline $51-60$ hours & - & - & 7 & 746 \\
\hline & 583 & 139041 & 713 & 155373 \\
\hline
\end{tabular}


Table 3. Days of the week available for ordinary hours of work.

\author{
Range \\ 5 days Mon - Fri \\ 5 days Mon - Sat \\ 5 days Mon - Sun \\ 4 days Mon - Sun \\ 4 days Mon - Fri, Sat \\ Other
}

Totals

\begin{tabular}{|rr}
\multicolumn{2}{c}{$\begin{array}{c}\text { Previous settlement } \\
\text { No. } \\
\text { Coverage }\end{array}$} \\
466 & 101354 \\
32 & 21413 \\
80 & 16660 \\
3 & 1015 \\
- & - \\
- & -
\end{tabular}

581
140442

\section{New contract \\ No. Coverage}

$\begin{array}{lr}456 & 95514 \\ 46 & 4632 \\ 201 & 37851 \\ 42 & 23030 \\ 11 & 2761 \\ 4 & 1120\end{array}$

760
163788 percent) of all workers covered by this set of collective employment contracts. Clock hours continue to be very prevalent but less so than before - 85 percent of comparable "old" settlements contained clock hours. There continue to be a number of important new contracts, covering comparatively large numbers of workers, which have done away with the traditional clock hours approach to employment. We have identified 207 contracts covering 49,000 workers which do not contain clock hours.

The data in Table 3 indicate that there are important changes occurring in the days of the week in which the ordinary hours of work can be worked. A growing number of new contracts are specifying that 5 days can be worked either Mon - Sat or Mon - Sun, and an important number of contracts covering a large number of workers are indicating that a 4 day week over any days of the week Mon - Sun is an option.

A detailed analysis of the data according to whether the new contract provides for a 4 or 5 day working week has revealed some interesting trends. There are major differences between industries with the "wholesale, retail, hotel" sector being significantly more likely to adopt the 4 days week than any other sector. On the other hand, the 4 day week has appeared in just 10 contracts in the manufacturing sector. There is some evidence that the 4 day week has resulted from a trade off over wages contracts introducing a 4 day week were significantly more likely to settle for a wage increase in excess of 5 percent than were contracts which maintained the 5 day week.

The data in Table 4 present the hours each day within which the ordinary hours are to be worked. There is considerable extension of the ordinary hours with starting hours for many employees coming back from the traditional $8.00 \mathrm{am}$ start to allow a $6.00 \mathrm{am}$ start without the payment of penal or overtime rates. The extension of the ordinary hours into the evening is even more marked with the traditional $6.00 \mathrm{pm}$ finish being replaced by finishes staggered from $6.30 \mathrm{pm}$ through to $10.00 \mathrm{pm}$.
A detailed analysis of the latest ordinary finishing time specified in the new contracts has been undertaken to focus on where the extensions in finishing hours are most likely to have been negotiated. Contracts in the "wholesale, retail, hotel" sector are significantly more likely than those in any other sector to contain ordinary hours of work after $6.00 \mathrm{pm}$ in the evening. Nearly 60 percent of contracts in that sector now contain later finishing provisions. The finance sector is the only other sector where there is a trend to later finishing hours with 27 percent of contracts in that sector specifying finishing hours later than $6.00 \mathrm{pm}$.

The span of hours in which the ordinary hours are to be worked has increased from a mean span of 10.6 hours under comparable settlements in the "old" system to a mean span of 11.2 hours under the new contracts - an average extension of half an hour per day within which ordinary clock hours can be worked. Now we all know, of course, that averages can distort the true extent of the changes. There were 216 contracts (covering 59,000 workers) where the span of hours within which clock hours could be worked was unchanged. Elsewhere very large changes occurred, curiously including a decrease in the available span in 66 contracts. The changed daily span of available clock hours is presented in Table 5.

A detailed analysis of the data was undertaken according to whether the span of ordinary hours decreased, remained the same, or increased. The "wholesale, retail, hotel" sector was significantly more likely than any other sector to experience increases in the daily span of clock hours. The community, social service sector was the most likely to experience no changes at all to the span of working hours. Significant difference in the level of wage settlements was identified. Contracts that increased the daily span of clock hours were significantly more likely to attract a wage increase greater than 1 percent than were contracts where no change to the clock hour span was agreed. Just on $\mathbf{8 0}$ percent of contracts experienced both no change in the span in clock hours and a zero wage increase. Clear statistical evidence exists of a trade off between extending the daily span of the ordinary hours of work and a wage increase. 
Table 4. Hours of the day available for ordinary hours of work

Starting hours
Before $6.00 \mathrm{am}$
$6.00 \mathrm{am}$
$6.30 \mathrm{am}$
$7.00 \mathrm{am}$
$7.30 \mathrm{am}$
$8.00 \mathrm{am}$
After $8.00 \mathrm{am}$

Finishing hours

Before $5.00 \mathrm{pm}$
$5.00 \mathrm{pm}$
$5.30 \mathrm{pm}$
$6.00 \mathrm{pm}$
$6.30 \mathrm{pm}$
$7.00 \mathrm{pm}$
$8.00 \mathrm{pm}$
$9.00 \mathrm{pm}$
$9.30 \mathrm{pm}$
$10.00 \mathrm{pm}$

10.00 pm - Midnight

\section{Previous settlement}

No. Coverage

$\begin{array}{rr}118 & - \\ 6 & 13413 \\ 128 & 224 \\ 174 & 20374 \\ 77 & 21452 \\ 1 & 58434 \\ & 40\end{array}$

New contract

No. Coverage

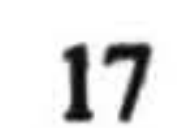

166

712

27302

816

38450

15001

32846

1455

\section{The Application of Overtime Payments}

The data in Table 6 report the changes to penal and overtime rates of pay. Again new contracts have been compared where possible with the predecessor settlement.

A number of clear trends exist. Penal and overtime rates for work outside clock hours still exist in most new contracts, however the rate for overtime work has changed markedly. These changes can be summarise as follows. First, triple time rates have all but disappeared. Second, double time ratesare far less freely available than previously. Third, work after the first three hours of overtime generally now continues on at time and a half rather than moving to

$\begin{array}{rrr}1586 & 42 & 1946 \\ 35491 & 143 & 28242 \\ 7763 & 65 & 5257 \\ 67442 & 198 & 43787 \\ 400 & 16 & 5060 \\ 656 & 21 & 3987 \\ 525 & 31 & 14087 \\ - & 19 & 5127 \\ - & 7 & 7339 \\ 74 & 6 & 1262 \\ & 56 & 261\end{array}$

double time. Fourth, work on Sunday and night work (10 $\mathrm{pm}$ to $6 \mathrm{am}$ ) generally continues to attract double time rates, however many contracts have moved to time and a half for the first three hours then double time for Sunday work. Exceptions are in the "wholesale, retail, hotel" sector, and for work scheduled as part of of an organised shift work arrangement. Fifth, time and a quarter has appeared in a small number of contracts covering however a large number of workers.

In addition, another important change which we have not been able to quantify has been observed. Previously many awards and collective agreements specified a minimum number of hours for payment of overtime rates,

Table 5. Changes to the span of available clock hours

$\begin{array}{lcrr}\text { Changed span (in hours) } & \text { No. of Contracts } & \text { Coverage } & \text { \% Coverage } \\ \text { Decreased span of hours } & 66 & 4408 & 4 \% \\ \text { No change } & 216 & 58584 & 55 \% \\ \text { One hour longer } & 51 & 7828 & 8 \% \\ \text { Two hours longer } & 65 & 9404 & 9 \% \\ \text { Three hours longer } & 21 & 10864 & 10 \% \\ \text { Four hours longer } & 14 & 10647 & 10 \% \\ \text { Five hours longer } & 3 & 2950 & 3 \% \\ \text { Six or more hours longer } & 6 & 998 & 1 \% \\ & & & 100 \%\end{array}$


particularly for Saturday and Sunday work. That minimum period was usually three hours. Our observation with the contracts we have examined is that such arrangements have largely disappeared and that overtime is now paid for the hours actually worked rather than minimum periods of engagement.

\section{Discussion}

This paper has examined three types of alterations to working time arrangements sought by employers to increase flexibility. First, the reduction (or extension) of the working week. The data shows little evidence of change to the working week. Employees who have traditionally worked a 37 and a half hour week appear to continue that arrangement as do workers who normally worked a 40 hour week. Nearly 7500 workers, however, can now be required to work an "ordinary" week in excess of 40 hours per week - something permissible but never required under the previous legislation.

Second, the scheduling of the hours worked each week by full time workers. While the Monday - Friday week remains standard for most workers, some quite dramatic changes have been identified. Some 26,000 workers can now work a four day week (usually of 10 hours on each of the four days) - a phenomenon rarely (if ever) seen in settlements under the Labour Relations Act. In addition, there has been a marked extension of the days of the week available for "ordinary" work to include Saturdays and Sundays. While there have been some liberalisations in the days of the week available, there have been greater liberalisations in the "clock hours" available each day. The available daily span has been increased by an average

Table 6. Overtime / penal rates of pay applicable

\section{Outside ordinary hours}

Flat dollar rate

Time and a quarter throughout

Time and a half throughout

Double time throughout

Time a half for $3 \mathrm{hrs}$, then double

Time a half for $4 \mathrm{hrs}$, then double

Time a half for $3 \mathrm{hrs}$, double at night

Time a half for $3 \mathrm{hrs}, 2 \mathrm{~T}$ for 5 , Triple

Other

Time in lieu

\section{Saturday}

Flat dollar rate

Time and a quarter throughout

Time and a half throughout

Double time throughout

Time a half for $3 \mathrm{hrs}$, then double

Time a half for $4 \mathrm{hrs}$, then double

Time a half, double after noon

Time a half for $3 \mathrm{hrs}, 2 \mathrm{~T}$ for 5 , Triple

Other

Time in lieu

\section{Sunday}

Flat dollar rate

Time and a quarter throughout

Time and a half throughout

Double time throughout

Time a half for $3 \mathrm{hrs}$, then double

Time a half for $4 \mathrm{hrs}$, then double

Double time for 8 hours, then triple

Other

Time in lieu

\section{Previous settlement}

No. Coverage

$\begin{array}{rr}3 & 84 \\ - & - \\ 4 & 1925 \\ 1 & 3 \\ 262 & 65825 \\ 2 & 35 \\ 288 & 70545 \\ 24 & 1980 \\ 6 & 2099 \\ 1 & 25\end{array}$

No

Coverage

$\begin{array}{rr}3 & 84 \\ 1 & 257 \\ 20 & 2823 \\ 36 & 28778 \\ 459 & 95499 \\ 3 & 122 \\ 25 & 2006 \\ 25 & 2040 \\ 2 & 1036 \\ 5 & 8255\end{array}$

No.

Coverage

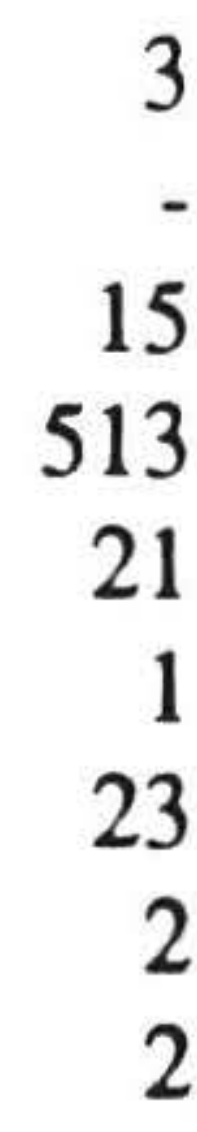

New contract

No. Coverage

$\begin{array}{rr}29 & 8846 \\ 6 & 5075 \\ 196 & 25352 \\ 4 & 170 \\ 248 & 67199 \\ 15 & 858 \\ 128 & 43016 \\ 4 & 287 \\ 52 & 7761 \\ 4 & 45\end{array}$

No. Coverage

$\begin{array}{rr}30 & 8871 \\ 9 & 6102 \\ 207 & 24875 \\ 25 & 20472 \\ 316 & 77027 \\ 21 & 893 \\ 14 & 2958 \\ 52 & 337 \\ 5 & 7874 \\ 5 & 9065\end{array}$

No. Coverage

8846

5078

24093

91526

12253

305

342

5460

9973 
of half an hour per day, to a span slightly in excess of 11 hours. The daily extensions have largely been in the available finishing times which have in some cases drifted out towards $10 \mathrm{pm}$.

Third, the application of overtime and penal payments. Overtime and penal rates are still freely available but often the rate has been reduced and some of the premiums previously available have gone. Workers are now more likely to be paid for the actual number of overtime hours worked rather than for minimum periods of engagement such as three hours. Triple time rates have gone. Double time rates are less freely available than previously but are still commonly available for night and Sunday work. Penal rates for Saturday afternoon work have drifted down to time and half - work previously usually attracting double time rates.

The changes observed are to some extent industry specific. The four day week is a phenomena available predominantly in the hotel, retail and restaurant sector; extended daily span of hours predominantly occur in the hotel, retail, restaurant and finance sectors. In the manufacturing sector, however, little change to working time arrangements has been observed. The changes reported are largely in industries that operate a 6 or 7 day a week operation - where new approaches to the flexible use of labour have been seized by employers eager take advantage of the liberalised statutory requirements. In other industries, such as manufacturing, some reductions have been negotiated but it is unclear what effect these changes have. Many employers have indicated during the course of this study that while there has been a reduction in conditions, that reduction has sometimes been a paper reduction - a reduction in the terms of the contract that has not been applied in practice - in other words some employers are paying better than their own enterprise contracts. The reason for this is linked with the perception of competitive advantage. Many employers will implement the reduction when their competitors do, in the meantime they are eager to maintain an efficient and happy workforce so have been reluctant to implement reductions in working conditions.

This last issue is an important consideration. Distinctions need to be made between the range of flexibility in "agreedupon working hours" and the practice arising from that agreement (Melvyn, 1991). The data reported in this paper focus on the agreements reached rather than the practices invoked. Labour scheduling in an enterprise may in fact be more flexible than that "permitted" or indicated in an employment contract so that the degree of flexibility currently available or practised needs to be assessed against "incremental extensions" or new departures or restrictions on current arrangements (Blyton, 1992). It is this pragmatic application of arrangements that is often hidden in any enquiry based upon an examination of statutory and contractual conditions such as the research reported herein. Determining the extent to which these employers are using their new found freedoms and flexibility Brequires a different workplace based study.
Notwithstanding this there can be no doubt that the liberalisation of New Zealand's employment laws has been seized by some employers to allow them greater flexibility in the scheduling of their workforce so as to either reduce or avoid the payment of overtime or penal payments. If the new contracts are for 40 "ordinary" hours on Thursday - Sunday in the hospitality industry or Wednesday - Saturday in the retail sector, and there has been no "buy-out" of the reduction in penal rates by an increased hourly rate, then there is an important saving in wage costs for the employer. In these situations, productivity gains are resulting simply from a reduction in the unit cost of wages rather than any reforms in terms of production, services, or the quality of either, and such gains may not be sustained in the medium or long term. In short, if hours alone are being changed to bring about flexibility and other flexibilities proposed by Brunhes and others are not pursued, then employee morale, and countervailing societal and familial pressures, may start to reverse the managerial ascendancy currently being exhibited. Productivity gains currently achieved may be short lived.

\section{Notes}

* This research was supported by grants from the Internal Grants Committee and the Faculty of Commerce and Administration, Victoria University of Wellington. The authors are grateful to James Moulder and Charlie Welch for research assistance.

1 "Freely" in this context means not only "easily available" but at "no cost to the recipient"!

\section{References}

Anxo, D and A. Bigsten 1989 Working hours and productivity in Swedish manufacturing Scandinavian Journal of Economics 91(3): 613619.

Bechtold, S., M. Brusco and M. Showalter 1991 A comparative evaluation of labour tour scheduling methods Decision Sciences 22(4): 683-619.

Blyton, P. 1985 Changes in working time: an international review. London, Croom Helm.

Blyton, P. 1992 Flexible times? Recent developments in temporal flexibility Industrial Relations Journal 23(1): 26-36.

Bosch, G. 1990 From 40 to 35 hours: reduction and flexibilisation of the working week in the Federal Republic of Germany International Labour Review 129(5): 611-627. 
Brunhes, B., J. Rojot and W. Wasserman 1989

Labour Market Flexibility: Trends in Enterprises Paris OECD.

Charlton, D. 1991 The rewards of annual hours Management Services 35(11): 16-19.

Do Rosario, L. 1992 Hard Labour: Japanese workers poised for shorter hours Far Eastern Economic Review 155(9): 55.

Harbridge, $\mathbf{R}$ and S. McCaw 1989 The first wage round under the Labour Relations Act 1987 : changing relative power New Zealand journal of industrial relations, 14 (2) 149 - 167.

Harbridge, $R$ and M. Dreaver 1989 Changing patterns of working time arrangements in registered collective settlements in New Zealand New Zealand journal of industrial relations 14 (3) 251 - 266.

Loucks, J and R. Jacob 1991 Tour scheduling and task assignment of a heterogeneous workforce: a heuristic approach Decision Sciences 22 (4): 719 738.

Macarov, D. 1991 Full employment is neither feasible nor desirable International Journal of Sociology and Social Policy 11 (1): 171-191.

Mayer, C. 1991 The Business of Leisure International Management (Europe Edition) 46 (6): 28-31.

Melvyn, P. 1991 Working Time: Third conference of the International Symposium on Working Time Conference Report Vienna, European Centre for Social Welfare Policy and Research.

Neifer-Dichmann, E. 1991 Working time reductions in the former Federal Republic of Germany: a dead end for employment policy International Labour Review 130(4): 511-522.

New Zealand Business Who's Who 1990 Fourth Estate Publications Wellington.

Pickard, J. 1992 The pros and cons of annual hours programs Personnel Journal 71(4): 92-97.

Storper, M and A. Scott 1990 Work organisation and local labour markets in an era of flexible production International Labour Review 129(5): 573-591. 